\section{Correlations between physical performance and muscle mass, strength, and quality in obese and normal-weight community-dwelling older Japanese women}

Koji Nonaka ${ }^{1}, \mathrm{PhD}$, Shin Murata ${ }^{2}, \mathrm{PhD}$, Kayoko Shiraiwa ${ }^{2}, \mathrm{PhD}$, Teppei Abiko ${ }^{2}$, $\mathrm{PhD}$, Akio Goda ${ }^{2}, \mathrm{PhD}$, Yuichi Yasufuku ${ }^{2}, \mathrm{MS}$, Hideki Nakano ${ }^{2}, \mathrm{PhD}$, Hiroaki Iwase $^{3}$, MS, Jun Horie ${ }^{2}$, PhD

\begin{abstract}
Background. Muscle strength correlates with physical performance and depends on muscle mass and quality, which may differ between obese and normal-weight older women. We aimed to compare obese and normal-weight older women in terms of muscle strength, mass, and quality to determine the correlation between physical performance and these muscle characteristics.
\end{abstract}

Methods. A total of 170 community-dwelling older women were categorised into normal-weight $(n=137)$ or obese $(n=33)$ group. Their knee extension strength ratio, leg muscle mass ratio and muscle quality, and physical performance (30-second chair stand test and timed up and go test) were assessed.

Results. Compared with the normal-weight group, the obese group had lower muscle strength ratio $(0.32$ vs $0.39, \mathrm{p}<0.001)$ and muscle mass ratio $(92.36$ vs $107.82, \mathrm{p}<0.001)$ but similar muscle quality and physical performance. The muscle strength ratio moderately correlated with physical performance in both groups, whereas the muscle mass ratio weakly to moderately correlated or tended to correlate with physical performance, except for 30-second chair stand test result in the normalweight group. Muscle quality correlated with physical performance in the normal-weight group but not in the obese group.

Conclusions. Obese older women had lower muscle strength ratio and muscle mass ratio but similar muscle quality, compared with normalweight older women. In obese older women, physical performance tended to correlate with muscle mass ratio rather than muscle quality.

Key words: Aged; Muscle strength; Obesity; Physical functional performance

\section{ORIGINAL ARTICLE}

\footnotetext{
Department of Rehabilitation, Faculty of Health Sciences, Naragakuen University, Nara, Japan

2 Department of Physical Therapy, Faculty of Health Sciences, Kyoto Tachibana University, Kyoto, Japan

Department of Physical Therapy, Faculty of Rehabilitation, Kobe International University, Kobe, Japan
}

Correspondence to: Koji Nonaka, Department of Rehabilitation, Faculty of Health Sciences, Naragakuen University, Nara, Japan. Email: nonaka@naragakuen-u.jp

\section{INTRODUCTION}

Muscle strength decreases with ageing, ${ }^{1}$ and its maintenance reduces the prevalence of functional limitation. ${ }^{2}$ Among community-dwelling older adults, leg function is highly predictive of subsequent disability. ${ }^{3}$ Knee extension strength and its impairment are associated with physical performance. ${ }^{4,5}$ The risk of falling (and possible subsequent fractures) is associated with a decline in the musculoskeletal function. ${ }^{6}$ Therefore, muscle strength is important for the health of older adults. 
Age-related loss of muscle strength refers to loss of both neuromuscular function and muscle mass and is the primary cause for muscle decline. ${ }^{7-9}$ However, other factors may contribute to the loss of muscle strength with ageing. ${ }^{10}$ In addition to muscle quantity, muscle quality (muscle strength relative to muscle mass) may be another determinant of loss of muscle strength with ageing. ${ }^{11}$

Body mass index (BMI) is associated with muscle mass and muscle quality. Obese individuals (BMI, $\left.\geq 25 \mathrm{~kg} / \mathrm{m}^{2}\right)$ tend to have greater muscle mass than normal-weight individuals (BMI, $18.5-22.9 \mathrm{~kg} / \mathrm{m}^{2}$ ). ${ }^{12}$ Muscle strength is expected to be greater in obese individuals than in normal-weight individuals. However, one study reported similar muscle strength in obese (BMI, $\geq 29 \mathrm{~kg} / \mathrm{m}^{2}$ ) and normal-weight (BMI, $\left.24-29 \mathrm{~kg} / \mathrm{m}^{2}\right)$ individuals. ${ }^{13}$ This conflicting evidence may be due to the association between low muscle mass and high muscle quality. ${ }^{14}$ There are treatment strategies to improve muscle mass and muscle quality. ${ }^{15}$ Given that muscle strength is associated with physical performance, ${ }^{5}$ we hypothesised that the correlations between muscle mass or quality and physical performance differ between obese and normal-weight individuals. This study aimed to determine the correlation between physical performance and muscle characteristics (strength, mass, and quality) in obese and normal-weight community-dwelling older women.

\section{METHODS}

This cross-sectional study was conducted in accordance with the Declaration of Helsinki and was approved by the ethics committee of the Kyoto Tachibana University (approval number: 18-26). Written informed consent was obtained from each participant. 253 community-dwelling older adults were recruited from Yasu City, Japan, through public information papers. Inclusion criteria were: (1) age $>60$ years, (2) no cognitive impairment (Mini-Mental State Examination score of $\geq 24$ ), and (3) ability to perform all measurements. Exclusion criteria were: (1) underweight (BMI, $<18.5 \mathrm{~kg} / \mathrm{m}^{2}$ ) and (2) cardiac pacemaker implanted. Of 253 community-dwelling older adults, 170 women were included for analysis (FIGURE). They were categorised to normal-weight (BMI, 18.5-24.9 kg/m²) and obese (BMI, $\geq 25 \mathrm{~kg} / \mathrm{m}^{2}$ ) groups, according to the Japanese criteria. The number of comorbidities under medical treatment in each participant was recorded.

Knee extension strength was measured. Participants were instructed to sit upright with their arms folded across their chest and the hip and knee

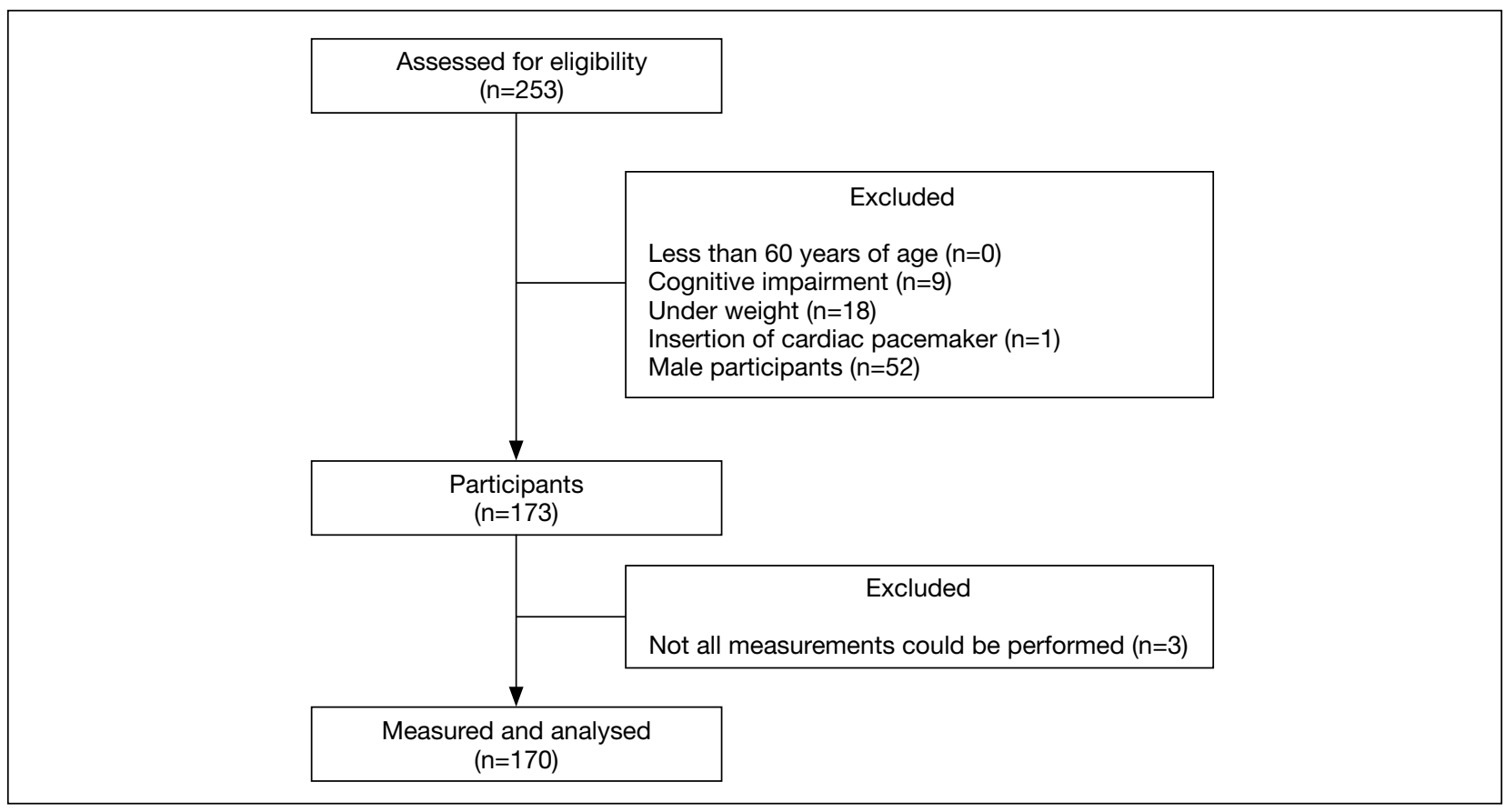

FigurE. Flowchart of recruitment of participants 
flexed at $90^{\circ}$, without changing posture during measurement. ${ }^{16}$ A hand-held dynamometer ( $\mu$ Tas F-1; Anima, Tokyo, Japan) was placed proximal to the ankle to measure maximal isometric muscle contraction. The intra-class correlation coefficient of measurements in older adults (aged 65-79 years) was $>0.8 .{ }^{17}$ The mean value of two measurements for each leg was used for analysis. The muscle strength ratio was defined as knee extension strength in $\mathrm{kg}$ / body weight in $\mathrm{kg}$. Muscle mass of both legs was measured using the bioelectrical impedance method with Inbody 470 (InBody Japan, Tokyo, Japan). The mean value of both legs was used for analysis. The muscle mass ratio was defined as muscle mass in $\mathrm{kg} /$ body weight in $\mathrm{kg}$. The muscle quality of legs was defined as the ratio of muscle strength in $\mathrm{kg}$ to muscle mass in $\mathrm{kg} .{ }^{18}$

Physical performance was measured using the 30-second chair stand test (CS-30) ${ }^{19}$ and timed up and go test (TUG).$^{20}$ For CS-30, participants were asked to sit in a chair (with the back straight, feet on the floor, and arms folded across the chest) and repeatedly rise to a full-standing position and then return to the initial seated position as fast as possible for $30 \mathrm{~s}$. For TUG, participants were asked to stand up from sitting in a chair without arm rests, walk 3 $\mathrm{m}$, turn around, walk back, and sit down on the chair again as fast as possible.

Using G*Power version 3.1.9.2 (Statistical Power Analyses, http://www.gpower.hhu.de), the sample size was calculated to be 44 based on the low correlation $(\mathrm{r}=0.40)$, with $\alpha$ set at 0.05 and power set at 0.80 . The ratio of normal-weight group to obese group was estimated to be approximately 3:1, based on our previous study. ${ }^{21}$ Therefore, a sample size of 176 was needed.

The Shapiro-Wilk test was used to verify whether data were normally distributed. The normal-weight group and obese group were compared using the Mann-Whitney $U$ test for non-normally distributed data (age, height, BMI, and TUG), the Levene test of homogeneity of variance for normally distributed data, the Welche $t$ test for data not exhibiting homogeneous variance (muscle strength ratio), the unpaired-t test for data exhibiting homogeneous variance, and the Chi-squared test for the prevalence of comorbidities. Correlations between physical performance (CS-30 and TUG) and muscle characteristics (strength, mass, and quality) were analysed using the Spearman correlation test or Pearson correlation test, as appropriate. A correlation coefficient (r) of 0.2-0.4, >0.4-0.7, and >0.7-0.9 indicated weak, moderate, and high correlations, respectively. Statistical analyses were performed using SPSS (version 24.0, IBM, USA). Statistical significance was set at $p<0.05$. For multiple betweengroup comparison on different muscle strength ratio, muscle mass ratio, and muscle quality, Bonferroni correction was performed with statistical significance set at $\mathrm{p}<0.016(0.05 / 3)$.

\section{RESULTS}

There were 137 women in the normal-weight group and 33 women in the obese groups (TABLE 1). The two groups were comparable in terms of age, height, and the prevalence of comorbidities. Compared with the normal-weight group, the obese group had lower muscle strength ratio (0.32 vs $0.39, \mathrm{p}<0.001$ ) and muscle mass ratio (92.36 vs 107.82, $\mathrm{p}<0.001$ ) but similar muscle quality and physical performance (CS-30 and TUG) [TABLE 2].

The muscle strength ratio moderately correlated with physical performance in both groups, whereas the muscle mass ratio weakly to moderately correlated or tended to correlate with physical performance, except for CS-30 in the normal-weight group (TABLE 3). Muscle quality moderately correlated with CS30 and weakly correlated with TUG in the normalweight group, but it did not correlate with physical performance in the obese group.

\section{DISCUSSION}

Our findings revealed that physical performance tended to correlate more with muscle strength ratio, compared with muscle mass ratio and muscle quality. Consistent with our results, muscle strength has been reported to correlate with CS-3022 and TUG. ${ }^{23}$ Muscle strength is important in maintaining or improving physical performance in both obese and normal-weight older women.

Upper leg muscle quality has been reported to moderately correlate with TUG $(r=-0.47){ }^{24}$ In our study, physical performance correlated with muscle quality in the normal-weight group but not in the obese group. Although obesity has been reported 
TABLE 1

Characteristics of normal-weight and obese older women

\begin{tabular}{|c|c|c|c|}
\hline Variable & Normal-weight group $(n=137)^{\star}$ & Obese group $(n=33)^{*}$ & $\mathrm{p}$ Value \\
\hline Age, y & $74.7 \pm 5.2$ & $74.2 \pm 5.8$ & 0.893 \\
\hline Height, cm & $151.4 \pm 5.2$ & $149.4 \pm 6.2$ & 0.098 \\
\hline Weight, kg & $49.1 \pm 5.1$ & $61.1 \pm 5.4$ & $<0.001$ \\
\hline Body mass index, $\mathrm{kg} / \mathrm{m}^{2}$ & $21.1 \pm 5.1$ & $27.4 \pm 1.6$ & $<0.001$ \\
\hline \multicolumn{4}{|l|}{ Comorbidities } \\
\hline Hypertension & $58(42.3)$ & $17(51.5)$ & 0.340 \\
\hline Hyperlipidaemia & $23(16.8)$ & $5(17.9)$ & 0.820 \\
\hline Orthopaedic diseases & $24(17.5)$ & $7(21.2)$ & 0.622 \\
\hline Stroke & $1(0.7)$ & $0(0.0)$ & 0.623 \\
\hline Diabetes mellitus & $8(5.8)$ & 5 (38.5) & 0.071 \\
\hline Rheumatoid arthritis & $3(2.2)$ & $0(0.0)$ & 0.391 \\
\hline Cardiovascular disease & $5(3.6)$ & $2(6.1)$ & 0.531 \\
\hline Pulmonary disease & $3(2.2)$ & $0(0.0)$ & 0.391 \\
\hline Renal disease & $2(1.5)$ & $0(0.0)$ & 0.485 \\
\hline Cancer & $3(2.2)$ & $0(0.0)$ & 0.391 \\
\hline Others & 26 (19.0) & 5 (15.2) & 0.609 \\
\hline
\end{tabular}

* Data are presented as mean \pm standard deviation or No. (\%) of patients

TABLE 2

Leg muscle strength ratio, muscle mass ratio, muscle quality and physical performance in normalweight and obese older women

\begin{tabular}{lccc}
\hline Variable & Normal-weight group $(\mathrm{n}=137)^{*}$ & Obese group $(\mathrm{n}=33)^{*}$ & $\mathrm{p}$ Value \\
\hline Muscle strength ratio & $0.39 \pm 0.09$ & $0.32 \pm 0.06$ & $<0.001$ \\
Muscle mass ratio & $107.82 \pm 10.11$ & $92.36 \pm 8.49$ & $<0.001$ \\
Muscle quality & $3.60 \pm 0.88$ & $3.50 \pm 0.68$ & 0.570 \\
$\begin{array}{l}\text { 30-second chair stand test, } \\
\text { repetition/30 sec }\end{array}$ & $21.44 \pm 6.22$ & $21.85 \pm 5.23$ & 0.731 \\
Timed up and go test, sec & $5.76 \pm 1.00$ & $5.90 \pm 0.98$ & 0.431 \\
\hline
\end{tabular}

* Data are presented as mean \pm standard deviation

TABLE 3

Correlations between physical performance and leg muscle strength ratio, muscle mass ratio, and muscle quality

\begin{tabular}{lccllll}
\hline Variable & \multicolumn{2}{c}{30 -second chair stand test } & & \multicolumn{2}{c}{ Timed up and go test } \\
\cline { 2 - 3 } & Normal-weight group & Obese group & & Normal-weight group & Obese group \\
\hline Muscle strength ratio & $r=0.500(p<0.001)$ & $r=0.518(p=0.002)$ & & $r=-0.466(p<0.001)$ & $r=-0.486(p=0.004)$ \\
Muscle mass ratio & $r=0.096(p=0.268)$ & $r=0.391(p=0.024)$ & & $r=-0.203(p=0.018)$ & $r=-0.569(p=0.001)$ \\
Muscle quality & $r=0.435(p<0.001)$ & $r=0.343(p=0.051)$ & & $r=-0.385(p<0.001)$ & $r=-0.248(p=0.164)$ \\
\hline
\end{tabular}

to be associated with lower muscle quality, ${ }^{25}$ our findings reported similar muscle quality in obese and normal-weight older women. The discrepancy may be due to (1) obese individuals have greater weight- bearing stress and thus higher muscle quality than normal-weight individuals, and (2) the muscle mass ratio is lower in obese than normal-weight individuals, and low muscle mass ratio increases 
weight-bearing stress to the muscle. Knee extensor muscle quality has been reported to increase after 12 weeks of strength training. ${ }^{26}$ Therefore, lower muscle mass ratio increases stress on the legs and hence increases muscle quality in obese individuals.

Thigh muscle volume (estimated by an equation that included age, sex, body weight, and thigh circumference) has been reported to weakly correlate with TUG $(r=-0.224)$ in older adults. ${ }^{27}$ Nonetheless, muscle thickness of the quadriceps femoris measured by ultrasonography was not correlated with TUG in older adult women. ${ }^{28}$ These findings suggest that correlation between muscle mass and TUG was low or absent. On the contrary, our study showed that the muscle mass ratio correlated or tended to correlate with both CS-30 and TUG in the obese group. Some obese older individuals do not have parallel growth of muscle mass with increasing weight..$^{29}$ Therefore, the muscle mass ratio tended to correlate with physical performance in obese older women but not in normal-weight older women.

Assessment of muscle strength rather than muscle mass or muscle quality is effective in identifying older women at risk of developing impaired mobility in later life..$^{30}$ Decline of muscle strength with ageing is a determinant of loss of muscle mass and muscle quality. ${ }^{9,11}$ Understanding the correlations between physical performance and muscle mass or muscle quality in obese and normal-weight older women may help them to maintain or improve their physical performance.

There are some limitations to this study. The cross-sectional design cannot determine causality. Men were excluded because of the small sample size. The muscle quality should have assessed through both muscle histological study and nervous system evaluation.

\section{CONCLUSION}

Obese older women had lower muscle strength ratio and muscle mass ratio but similar muscle quality, compared with normal-weight older women. In obese older women, physical performance tended to correlate with muscle mass ratio rather than muscle quality. Obese older adults should perform aerobic exercises to prevent muscle mass decrease and to reduce body weight so as to increase muscle mass ratio to maintain or improve physical performance.

\section{ACKNOWLEDGMENTS}

This research was supported by a JSPS KAKENHI Grant (16H05602 and 17K01808). We would like to thank Editage (www.editage.jp) for English language editing.

\section{DECLARATION}

The authors have no conflict of interest to disclose.

\section{REFERENCES}

1. Lindle RS, Metter EJ, Lynch NA, et al. Age and gender comparisons of muscle strength in 654 women and men aged 20-93 yr. J Appl Physiol (1985) 1997;83:1581-7. Crossref

2. Brill PA, Macera CA, Davis DR, Blair SN, Gordon N. Muscular strength and physical function. Med Sci Sports Exerc 2000;32:4126. Crossref

3. Guralnik JM, Ferrucci L, Simonsick EM, Salive ME, Wallace RB. Lower-extremity function in persons over the age of 70 years as a predictor of subsequent disability. N Engl J Med 1995;332:55661. Crossref

4. Bijlsma AY, Meskers CG, van den Eshof N, et al. Diagnostic criteria for sarcopenia and physical performance. Age (Dordr) 2014;36:275-85. Crossref

5. Ferrucci L, Guralnik JM, Buchner D, et al. Departures from linearity in the relationship between measures of muscular strength and physical performance of the lower extremities: the Women's Health and Aging Study. J Gerontol A Biol Sci Med Sci 1997;52:M275-85. Crossref

6. Macrae PG, Lacourse M, Moldavon R. Physical performance measures that predict faller status in community-dwelling older adults. J Orthop Sports Phys Ther 1992;16:123-8. Crossref

7. Rolland Y, Czerwinski S, Abellan Van Kan G, et al. Sarcopenia: its assessment, etiology, pathogenesis, consequences and future perspectives. J Nutr Health Aging 2008;12:433-50. Crossref

8. Aagaard P, Suetta C, Caserotti P, Magnusson SP, Kjaer M. Role of the nervous system in sarcopenia and muscle atrophy with aging: strength training as a countermeasure. Scand J Med Sci Sports 2010;20:49-64. Crossref

9. Brooks SV, Faulkner JA. Skeletal muscle weakness in old age: underlying mechanisms. Med Sci Sports Exerc 1994;26:4329. Crossref

10. Kallman DA, Plato CC, Tobin JD. The role of muscle loss in the age-related decline of grip strength: cross-sectional and longitudinal perspectives. J Gerontol 1990;45:M82-8. Crossref

11. Goodpaster BH, Park SW, Harris TB, et al. The loss of skeletal muscle strength, mass, and quality in older adults: the health, aging and body composition study. J Gerontol A Biol Sci Med Sci 2006;61:1059-64. Crossref

12. Woo J, Leung J, Kwok T. BMI, body composition, and physical functioning in older adults. Obesity (Silver Spring) 2007;15:188694. Crossref

13. Rolland Y, Lauwers-Cances V, Pahor M, Fillaux J, Grandjean $\mathrm{H}$, Vellas B. Muscle strength in obese elderly women: effect of recreational physical activity in a cross-sectional study. Am J Clin Nutr 2004;79:552-7. Crossref

14. Barbat-Artigas S, Filion ME, Plouffe S, Aubertin-Leheudre M. Muscle quality as a potential explanation of the metabolically healthy but obese and sarcopenic obese paradoxes. Metab Syndr 
Relat Disord 2012;10:117-22. Crossref

15. Fragala MS, Kenny AM, Kuchel GA. Muscle quality in aging: a multi-dimensional approach to muscle functioning with applications for treatment. Sports Med 2015;45:641-58. Crossref

16. Bohannon RW. Test-retest reliability of hand-held dynamometry during a single session of strength assessment. Phys Ther 1986;66:206-9. Crossref

17. Katoh M, Isozaki K, Sakanoue N, Miyahara T. Reliability of isometric knee extension muscle strength measurement using a hand-held dynamometer with a belt: a study of test-retest reliability in healthy elderly subjects. J Phys Ter Sci 2010;22:35963. Crossref

18. Tsugawa A, Ogawa $Y$, Takenoshita N, et al. Decreased muscle strength and quality in diabetes-related dementia. Dement Geriatr Cogn Dis Extra 2017;7:454-62. Crossref

19. Jones CJ, Rikli RE, Beam WC. A 30-s chair-stand test as a measure of lower body strength in community-residing older adults. Res Q Exerc Sport 1999;70:113-9. Crossref

20. Podsiadlo D, Richardson S. The timed “Up \& Go": a test of basic functional mobility for frail elderly persons. J Am Geriatr Soc 1991;39:142-8. Crossref

21. Nonaka K, Murata S, Shiraiwa K, et al. Physical characteristics vary according to body mass index in Japanese communitydwelling elderly women. Geriatrics (Basel) 2018;3.pii:E87. crossref

22. McCarthy EK, Horvat MA, Holtsberg PA, Wisenbaker JM Repeated chair stands as a measure of lower limb strength in sexagenarian women. J Gerontol A Biol Sci Med Sci 2004;59:120712. Crossref
23. Schaubert KL, Bohannon RW. Reliability and validity of three strength measures obtained from community-dwelling elderly persons. J Strength Cond Res 2005;19:717-20. Crossref

24. Shiraishi N, Suzuki Y, Hirose T, et al. Predictors of decreased skeletal muscle mass in community-dwelling older adults. J Aging Res Clin Pract 2015;4:74-80.

25. Koster A, Ding J, Stenholm S, et al. Does the amount of fat mass predict age-related loss of lean mass, muscle strength, and muscle quality in older adults? J Gerontol A Biol Sci Med Sci 2011;66:888-95. Crossref

26. Correa CS, Baroni BM, Radaelli R, et al. Effects of strength training and detraining on knee extensor strength, muscle volume and muscle quality in elderly women. Age (Dordr) 2013;35:1899904. Crossref

27. Chang CI, Chen CY, Wu CH, Hsiung CA, Chen CY. Correlates of thigh muscle index with physical performance in ambulatory geriatric patients. J Aging Res Clin Pract 2012;1:44-50.

28. Nishihara K, Kawai H, Kera T, et al. Correlation of physical function with the thickness of multiple muscles of the quadriceps femoris in community-dwelling elderly individuals. Clin Interv Aging 2018;13:1945-51. Crossref

29. Stenholm S, Harris TB, Rantanen T, Visser M, Kritchevsky SB, Ferrucci L. Sarcopenic obesity: definition, cause and consequences. Curr Opin Clin Nutr Metab Care 2008;11:693-700. crossref

30. McGregor RA, Cameron-Smith D, Poppitt SD. It is not just muscle mass: a review of muscle quality, composition and metabolism during ageing as determinants of muscle function and mobility in later life. Longev Healthspan 2014;3:9. Crossref 